\title{
Dynamic hesitant fuzzy linguistic group decision-making from a reliability perspective
}

\author{
MA Zhenzhen ${ }^{1}$, PONNAMBALAM Kumaraswamy ${ }^{2}$, ZHU Jianjun ${ }^{1, *}$, and ZHANG Shitao ${ }^{3}$ \\ 1. College of Economics and Management, Nanjing University of Aeronautics and Astronautics, Nanjing 211106, China; \\ 2. Department of Systems Design Engineering, University of Waterloo, Waterloo N2L 3G1, Canada; \\ 3. School of Mathematics \& Physics Science and Engineering, Anhui University of Technology, Ma'anshan 243002, China
}

\begin{abstract}
A dynamic hesitant fuzzy linguistic group decisionmaking (DHFLGDM) problem is studied from the perspective of information reliability based on the theory of hesitant fuzzy linguistic term sets (HFLTSs). First, an approach is applied to transform the dynamic HFLTSs (DHFLTSs) into a set of proportional linguistic terms to eliminate the time dimension. Second, expert reliability is measured by considering both group similarity and degree of certainty, and an optimization method is employed to quantify the linguistic terms by maximizing the group similarity. Third, through computing the attribute stability as well as its reliability, a combination rule which considers both reliability and weight is proposed to aggregate the information, and then the aggregated grade values and degree of stability are used to make a selection. Finally, the application and feasibility of the proposed method are verified through a case study and method comparison.
\end{abstract}

Keywords: dynamic decision-making, hesitant fuzzy linguistic term sets (HFLTSs), proportional linguistic terms, group similarity, degree of certainty.

DOI: $10.21629 /$ JSEE.2018.05.12

\section{Introduction}

Multi-attribute decision-making [1] is a situation in which decision-makers evaluate a finite set of alternatives under multiple attribute constraints. It is widely applied in many real cases such as water supply infrastructure planning [2], environmental performance [3], and farmer's behavior [4]. As an increasingly complex social and economic environment leads to more complicated decision-making systems, it is difficult for a single decision-maker to satisfy all decision-making requirements. Thus, group decisionmaking becomes a common decision mode instead of

\footnotetext{
Manuscript received November 13, 2017.

*Corresponding author.

This work was supported by the National Natural Science Foundation of China (71171112; 71502073; 71601002), the Scientific Innovation Research of College Graduates in Jiangsu Province (KYZZ15_0094), and the Anhui Provincial Natural Science Foundation (1708085MG168).
}

individual decision-making [5]. In many cases, decisionmakers often face uncertainty due to their bounded cognitive compacity and numerous complicated factors, and thus tend to use different uncertain formats to express their opinions, such as fuzzy numbers [6], probabilities [7], grey numbers [8] and linguistic terms [9]. Among these formats, the natural language is not only closer to human thinking but also more intuitive and easier to express [10], and has been widely studied in many group decision-making problems $[11,12]$. However, in some real-world applications, decision-makers may have certain hesitancy on some attributes or alternatives, and only one linguistic term is insufficient to accurately express the experts' opinions [13]. In order to address this issue, the theory of hesitant fuzzy linguistic term sets (HFLTSs) deserves a deep study.

HFLTSs, which often contain one or more linguistic terms, are useful to increase the flexibility and accuracy of information expression [14]. Many studies [15-17] have been employed on the comparison and integration methods of HFLTSs. Among these methods, the linguistic distribution method [17] is a direct and easy way, which assigns symbolic proportions (probabilities) to all linguistic terms more explicitly compared with other methods. In order to objectively and precisely obtain the probability of each linguistic term in an HFLTS, Chen et al. [18] proposed proportional HFLTSs to solve this problem. However, these studies do not consider information reliability of experts as it is useful to measure decision-making validity and accuracy.

In uncertain group decision-making, information reliability is one of the most competitive advantages for the problem to reduce decision-making risks [19]. In some cases, decision-makers have to provide a solution for the problems in spite that the information they utilize is inherently unverifiable, which may lead to a great loss or high decision-making risk. For example, when producing 
a new commercial aircraft, if experts severely overestimate its cost, the following processes will be greatly affected, resulting in great loss on both production duration and resources [20]. However, these deficiencies can be compensated for if the information reliability is considered in the decision process [21]. Moreover, HFLTSs often refer to certain hesitancy as well as some uncertainty, thus their reliability should be studied to improve decision-making accuracy.

Some studies have been identified on information reliability [22-24]. Among these studies, the information reliability of experts is generally measured from the perspective of group distance, such as group similarity [22,23] and dissimilarity [24]. Group conflict is likely to exist among the decision-makers as they often have distinct views on same problems owing to the differences in their technical experience, cultural level, social status, and other aspects. Group similarity, measuring the distance between one expert's opinion and group opinions, is useful to overcome the inadequacies associated with conflicts and biases of group opinions [25]. It has been successfully studied by many scholars on HFLTSs [26-28]. However, the single use of group similarity is not sufficient to reflect the reliability as it ignores the impact of uncertainty. According to Klir and Yuan [29], there are three kinds of uncertainty involved in uncertain theories, i.e., fuzziness, discord and nonspecificity, and a linguistic set refers to the nonspecificity. Thus, HFLTSs have certain nonspecificity. The nonspecificity can be measured by the amount of uncertainty [30]. Then, Frikha [31] measured the information reliability of experts by considering both amount of uncertainty and group conflicts. Based on this idea, one aim of this paper is to study the information reliability from perspectives of group similarity and degree of certainty.

Many decision-making problems are characterized by the complexity and a long-time span [32], and thus the methods to solve them need to be studied incorporating the view of the time dimension. Dynamic linguistic decision-making is widely studied by many scholars, such as dynamic hesitant fuzzy aggregation operators [33], linguistic granularity optimization methods [34,35], incomplete weight generation methods [36], and group consensus [37,38]. However, these studies do not consider the information reliability. We therefore propose a new dynamic hesitant fuzzy linguistic group decision-making (DHFLGDM) method by considering the reliability from perspectives of the defined degree of group similarity and degree of certainty based on the probability theory and linguistic granulation optimization method. Specifically, based on the HFLTSs of multiple stages, the degree of certainty of experts is calculated, and a method is proposed to obtain the probability distribution of linguistic terms.
Then, a linguistic granulation optimization method is employed by maximizing the group similarity. Moreover, information reliability of experts is measured by considering the group similarity and degree of certainty. In addition, the stability of attributes is also measured to help obtain the attribute reliability. Finally, both aggregated grade values and degree of stability of alternatives are considered to generate the ranking order for the alternatives.

The main contributions of the paper are: (i) a linguistic granulation optimization model is built by considering the group similarity, and the reliability for HFLTSs is measured from perspectives of two criteria, and (ii) based on the probability theory, both the reliabilities and weights of experts and attributes are considered during the aggregation process. In addition, the proposed method can be applied in many decision-making problems such as alternative selection and performance evaluation.

The remainder of this paper is structured as follows. Section 2 mainly introduces some relevant basic concepts. Section 3 presents the proposed method. Section 4 discusses the case study. Section 5 identifies the possible areas for future research.

\section{Preliminaries}

In this section, we introduce several basic definitions and notions involved in our research.

\subsection{Basic concepts of HFLTSs}

HFLTS approaches are an extension of linguistic approaches based on fuzzy set theory [18]. A linguistic term set is defined by an ordered structure that contains a set of ordered linguistic variables [10]. Let a linguistic set be $S=\left\{s_{0}, s_{1}, \ldots, s_{g}\right\}$, where the granularity of the set is $g+1$ (an odd number). $S$ satisfies two properties. (i) If $\alpha \geqslant \beta$, there is $s_{\alpha} \geqslant s_{\beta}$. (ii) $n e g\left(s_{\alpha}\right)=s_{\beta}$, where $n e g$ is the negation operator of the linguistic terms and $\beta=g-\alpha$.

Definition 1 [13] Suppose that a linguistic set is expressed by $S=\left\{s_{0}, s_{1}, \ldots, s_{g}\right\}$, an ordered subset of consecutive linguistic terms on $S$ is defined as an HFLTS which is represented by $H_{s}=\left\{s_{a} \mid s_{a} \in S\right\}$.

Definition 2 [26] Let a linguistic set be $S=$ $\left\{s_{0}, s_{1}, \ldots, s_{g}\right\}$, and $p_{k}$ be the corresponding probability of $s_{k}$, where $s_{k} \in S, \sum_{k=0}^{g} p_{k}=1$, and $k=0,1, \ldots, g$. Then, $P=\left\{\left\langle s_{k}, p_{k}\right\rangle \mid k=0,1, \ldots, g\right\}$ is called the proportional linguistic pairs of $S$, and its corresponding expectation is defined by $E(P)=\sum_{k=0}^{g} N S\left(s_{k}\right) p_{k}$, where $N S\left(s_{k}\right)$ is the numerical scale of $s_{k}$. 


\subsection{Measures of uncertainty}

In the literature, there are two kinds of theories to measure the information uncertainty [30]. One is a classical theory in which the set does not refer to any probability, like the Hartley measure [39]. The other one is an extension theory to deal with the sets that involve the probabilities, like the amount of uncertainty [40].

Definition 3 (Hartley measure [39]) Let $X$ be a frame of discernment, and let $A$ be any subset of $X$. Then, the Hartley measure is defined as

$$
H(A)=\log _{2}(|A|)
$$

where $|\cdot|$ denotes the cardinality of $A$.

Definition 4 (Amount of uncertainty [40]) Let $X$ be a finite frame of discernment, and $p_{k}$ be the corresponding probability of $k(k \in X)$. Then, the amount of uncertainty is defined as

$$
A U=\max \left[-\sum_{k \in X} p_{k} \log _{2} p_{k}\right]
$$

where the symbol maximum is used to keep the probability distribution consistent with the given probability. Thus, in order to satisfy this requirement, suppose $p_{k}^{*}$ is the given probability of $k$, then $p_{k}$ should satisfy the constraints as follows:

$$
\begin{gathered}
p_{k} \in[0,1], \quad \forall k \in X, \quad \sum_{k \in X} p_{k}=1, \\
p_{k}^{*} \leqslant p_{k} \leqslant 1-\sum_{k^{\prime} \in X} p_{k^{\prime}}^{*}+p_{k}^{*} .
\end{gathered}
$$

\section{The proposed method}

In this section, a method to obtain the proportional linguistic pairs is proposed based on the dynamic HFLTSs (DHFLTSs). Then, information reliability is measured by the defined group similarity and degree of certainty. In addition, we provide a definition for the degree of stability which is measured by the amount of uncertainty, and consider it as a measure of the information reliability of one alternative with respect to each attribute. Finally, a discussion on how to get a ranking order is also presented in this section.

Suppose $T=\left\{t_{1}, t_{2}, \ldots, t_{L}\right\}\left(t_{l} \in T, l=1,2, \ldots, L\right)$ is a set of multiple stages and $A=\left\{a_{1}, a_{2}, \ldots, a_{M}\right\}$ $\left(a_{i} \in A, i=1,2, \ldots, M\right)$ is a set of alternatives. Each alternative is assessed with respect to a predefined attribute set $C=\left\{c_{1}, c_{2}, \ldots, c_{N}\right\}\left(c_{j} \in C, j=1,2, \ldots, N\right)$, and the weight vector of attributes is assumed to be $\boldsymbol{w}=\left(w_{1}, w_{2}, \ldots, w_{n}\right)$, where $w_{j} \in[0,1], \sum_{j=1}^{N} w_{j}=1$.
Suppose a set of experts is $E=\left\{e^{1}, e^{2}, \ldots, e^{K}\right\}$ and $\boldsymbol{\lambda}=\left(\lambda^{1}, \lambda^{2}, \ldots, \lambda^{K}\right)$ is the corresponding weight vector, where $\lambda^{k} \in[0,1], k=1,2, \ldots, K, \sum_{k=1}^{K} \lambda^{k}=1$. Assume $S=\left\{s_{0}, s_{1}, \ldots, s_{g}\right\}$ is a predefined linguistic term set, where $s_{0} \prec s_{1} \prec \cdots \prec s_{g}$, and thus $N S\left(s_{0}\right)<N S\left(s_{1}\right)<\cdots<N S\left(s_{g}\right)$. Some hesitancy may exist among the experts so that the information given by them is formulated as the HFLTSs. Let $h_{i j}^{k l}\left(h_{i j}^{k l} \in S\right)$ denote the assessment of the expert $e^{k}$ on the alternative $a_{i}$ with respect to the attribute $c_{j}$ at the stage $t_{l}$. The key work is to identify a method on information aggregation from the reliability perspective.

\subsection{Generation of probability distribution based on DHFLTSs}

HFLTSs are helpful to improve the elicitation of linguistic information when decision-makers have some hesitancy on several alternatives or attributes [13]. For example, a commercial aircraft manufacture asks three experts to evaluate one potential supplier of the avionics system, suppose that $S=\left\{s_{0}, s_{1}, s_{2}, s_{3}, s_{4}\right\}$. The first expert has no hesitancy on the alternative, providing the linguistic variable $s_{3}$; the second expert hesitates between $s_{3}$ and $s_{4}$; the third expert provides the assessment utilizing $s_{2}$ and $s_{3}$. Obviously, the classical linguistic term expression is a special case of HFLTSs which can increase the flexibility and richness of the linguistic elicitation. Generally, it is common for different decision-makers to have different degrees of hesitancy on the same alternative owing to the differences in their social experience, cultural level, social status, and other aspects [34]. Especially, in a dynamic situation, experts often have some hesitancy since they probably have difficulty in acquiring the comprehensive information when the performance of alternatives is variable. Thus, how to deal with the hesitant information of experts in dynamic decisionmaking deserves a deep research.

In a DHFLGDM problem, the key work is to aggregate the information of multiple stages. The common methods mainly study how to generate the weights of stages $[33,36]$. However, these methods refer to more or less subjective information and thus may generate different results using different subjective requirements. In order to objectively realize the information fusion of multiple stages, a method to transform the DHFLTSs into the proportional linguistic terms is applied in the work as it does not need any subjective values. Furthermore, this method has two advantages: (i) It assigns probabilities to all linguistic variables very explicitly, helping decision-makers clearly understand the performance distribution of alternatives; (ii) It can reflex the development stability of alternatives, and a 
dispersed linguistic probability distribution of one alternative means a poor stability of its performance and thus a higher decision-making risk.

In many practical problems, the probabilities are commonly generated by dividing the number of occurrences of one object by the total number of experiments. For example, the climate of one area has been investigated for 30 years; during these years, the flood occurred four times, the drought occurred three times, other years were normal, then the probability of flood is 0.13 , the probability of drought is 0.1 . Based on this idea, a transformation method is proposed to deal with the DHFLTSs in this section.

Let $T_{i j, i^{\prime}}^{k l}$ denote the times of $s_{i^{\prime}}\left(i^{\prime}=0,1, \ldots, g\right)$ in $h_{i j}^{k l}$, where $T_{i j, i^{\prime}}^{k l}=0$ or 1 , and $T_{i j, 0}^{k l}+\cdots+T_{i j, g}^{k l} \leqslant g+1$. For example, suppose an HFLTS is $\left\{s_{1}, s_{2}\right\}$, then there are $T_{i j, 1}^{k l}=1, T_{i j, 2}^{k l}=1$ and $T_{i j, i^{\prime}}^{k l}=0\left(i^{\prime}=0,1, \ldots, g ; i^{\prime} \neq 1\right.$ and 2). Let $T_{i j, i^{\prime}}^{k}$ be the corresponding times of $s_{i^{\prime}}$ by combining all stages, where $T_{i j, i^{\prime}}^{k}=\sum_{l=1}^{L} T_{i j, i^{\prime}}^{k l}$.

Definition 5 Let $s_{i j, i^{\prime}}^{k}$ be a linguistic term that is given by the expert $e^{k}$ on the alternative $a_{i}$ with respect to the attribute $c_{j}$. Then, the probability $p_{i j, i^{\prime}}^{k}$ of $s_{i j, i^{\prime}}^{k}$ is defined as

$$
p_{i j, i^{\prime}}^{k}=\frac{T_{i j, i^{\prime}}^{k}}{T_{i j, 0}^{k}+\cdots+T_{i j, g}^{k}}
$$

where $p_{i j, i^{\prime}}^{k} \in[0,1]$ and

$$
\sum_{i^{\prime}=0}^{g} p_{i j, i^{\prime}}^{k}=\frac{\sum_{i^{\prime}=0}^{g} T_{i j, i^{\prime}}^{k}}{T_{i j, 0}^{k}+\cdots+T_{i j, g}^{k}}=1 .
$$

Then we get the ordered proportional linguistic pairs expressed by

$$
\begin{gathered}
P_{H_{s}}= \\
\left\{\left(s_{i j, i^{\prime}}^{k}, p_{i j, i^{\prime}}^{k}\right) \mid s_{i j, i^{\prime}}^{k} \in S, \quad i=1,2 \ldots, M ;\right. \\
\left.j=1,2, \ldots, N ; k=1,2, \ldots, K ; i^{\prime}=0,1, \ldots, g\right\} .
\end{gathered}
$$

When it is a static problem, the above method is also suitable to get the corresponding linguistic probabilities. Let $T_{i j, i^{\prime}}^{\prime k}$ denote the times of $s_{i^{\prime}}\left(i^{\prime}=1,2, \ldots, g\right)$ in the HFLTS $h_{i j}^{k}$, where $T_{i j, i^{\prime}}^{\prime k}=0$ or 1 , and $T_{i j, 0}^{\prime k}+\cdots+$ $T^{\prime k}{ }_{i j, g} \leqslant g+1$, then the corresponding probability is expressed by

$$
p_{i j, i^{\prime}}^{\prime k}=\frac{T_{i j, i^{\prime}}^{k}}{T_{i j, 0}^{\prime k}+\cdots+T_{i j, g}^{\prime k}}
$$

with ${p^{\prime}}_{i j, i^{\prime}}^{k} \in[0,1]$ and $\sum_{i^{\prime}=0}^{g}{p^{\prime}}_{i j, i^{\prime}}^{k}=1$.
For example, when there is only one stage, suppose an HFLTS is $\left(s_{5}, s_{6}\right)$, then we can have $T_{i j, 5}^{k}=1$ and $T_{i j, 6}^{k}=$ 1 , others equal zero, then $p_{i j, 5}^{k}=0.5$ and $p_{i j, 6}^{k}=0.5$. Comprehensively, the idea to determine the probabilities of linguistic terms is shown in Fig. 1.

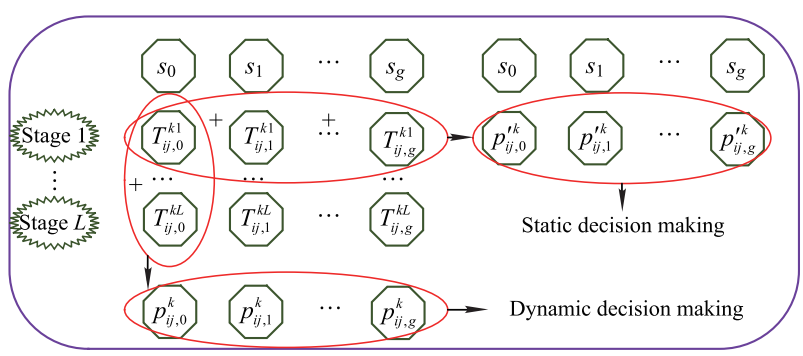

Fig. 1 Idea of determining probabilities of linguistic terms

\subsection{Generation of information reliability of experts}

To estimate the reliability of experts, two kinds of criteria are adopted in the proposed approach, i.e., group similarity and degree of certainty. Though the criteria presented in the work may not be exhaustive, they can contribute to an efficient evaluation of expert reliability and thus should be considered as a possible set of criteria for the reliability measurement.

\subsubsection{An approach to measure the group similarity}

As experts always have different cognitions in a group decision-making problem, reaching a certain degree of similarity is a critical step in obtaining a valid solution [38], and thus increases the effectiveness and acceptability of the decision-making. In practice, if several individual experts have some extreme opinions, they may enhance group conflicts among experts and thus have an adverse impact on the final decision. In order to solve this issue, group similarity is helpful to weaken the influence of these individual experts, making the result more consistent with most experts. However, full similarity, which refers to the state of total agreement, is hard to achieve in practice [41]. Therefore, in the work, we aim to improve the group similarity and consider it as a measure of information reliability of experts in the work.

There are two categories of methods which are used to compute the group similarity [28]: (i) distance to the collective preference; (ii) distance between experts. This paper adopts the second method.

Definition 6 Suppose two groups of ordered proportional linguistic pairs are expressed as $P_{H_{s}}^{k}=\left\{\left(s_{i j, i^{\prime}}^{k}, p_{i j, i^{\prime}}^{k}\right) \mid s_{i j, i^{\prime}}^{k} \in S\right\}$ and $P_{H_{s}}^{k^{\prime}}=$ $\left\{\left(s_{i j, i^{\prime}}^{k^{\prime}}, p_{i j, i^{\prime}}^{k^{\prime}}\right) \mid s_{i j, i^{\prime}}^{k^{\prime}} \in S\right\} \quad\left(k, k^{\prime}=1,2, \ldots, K\right.$ and $k \neq k^{\prime}$ ), then the degree of group similarity between 
two experts is defined as

$$
S M_{i j}^{k k^{\prime}}=1-\frac{\left|\sum_{i^{\prime}=0}^{g}\left(N S\left(s_{i^{\prime}}\right) p_{i j, i^{\prime}}^{k}-N S\left(s_{i^{\prime}}\right) p_{i j, i^{\prime}}^{k^{\prime}}\right)\right|}{N S\left(s_{g}\right)-N S\left(s_{0}\right)} .
$$

Corollary $1 S M_{i j}^{k k^{\prime}}$ has four properties: (i) $0 \leqslant$ $S M_{i j}^{k k^{\prime}} \leqslant 1$; (ii) $S M_{i j}^{k k^{\prime}}=S M_{i j}^{k^{\prime} k}$; (iii) if $P_{i j}^{k}=$ $P_{i j}^{k^{\prime}}$ (i.e., $\left.p_{i j, i^{\prime}}^{k}=p_{i j, i^{\prime}}^{k^{\prime}}\right), S M_{i j}^{k k^{\prime}}=1$; (iv) if $P_{i j}^{k}=$ $\left\{\left(s_{i j, 0}^{k}, 1\right)\right\}, P_{i j}^{k^{\prime}}=\left\{\left(s_{i j, g}^{k^{\prime}}, 1\right)\right\}$ or $P_{i j}^{k}=\left\{\left(s_{i j, g}^{k}, 1\right)\right\}$, $P_{i j}^{k^{\prime}}=\left\{\left(s_{i j, 0}^{k^{\prime}}, 1\right)\right\}, S M_{i j}^{k k^{\prime}}=0$.

Proof (i) Obviously, there is $\mid \sum_{i^{\prime}=0}^{g} N S\left(s_{i^{\prime}}\right) p_{i j, i^{\prime}}^{k}-$ $\sum_{i^{\prime}=0}^{g} N S\left(s_{i^{\prime}}\right) p_{i j, i^{\prime}}^{k^{\prime}} \mid \geqslant 0$, so we have $S M_{i j}^{k k^{\prime}} \leqslant 1$. When $P_{i j}^{k}=P_{i j}^{k^{\prime}}$, there is $S M_{i j}^{k k^{\prime}}=1$; when $\sum_{i^{\prime}=0}^{g} N S\left(s_{i}^{\prime}\right) p_{i j, i^{\prime}}^{k}-$ $\sum_{i^{\prime}=0}^{g} N S\left(s_{i}^{\prime}\right) p_{i j, i^{\prime}}^{k^{\prime}}=\sum_{i^{\prime}=0}^{g} N S\left(s_{i}^{\prime}\right)\left(p_{i j, i^{\prime}}^{k}-p_{i j, i^{\prime}}^{k^{\prime}}\right) \geqslant 0$ and $P_{i j}^{k} \neq P_{i j}^{k^{\prime}}$, because of $\sum_{i^{\prime}=0}^{g} P_{i j, i^{\prime}}^{k}=1$ and $\sum_{i^{\prime}=0}^{g} P_{i j, i^{\prime}}^{k^{\prime}}=1$, there must exist at least one group of $k^{\prime}$ and $k$ to get that $p_{i j, i^{\prime}}^{k}-p_{i j, i^{\prime}}^{k^{\prime}}<0$, as there is $N S\left(s_{0}\right)<N S\left(s_{1}\right)<\cdots<$ $N S\left(s_{g}\right)$, then we have

$$
\begin{gathered}
\sum_{i^{\prime}=0}^{g} N S\left(s_{i^{\prime}}\right)\left(p_{i j, i^{\prime}}^{k}-p_{i j, i^{\prime}}^{k^{\prime}}\right) \leqslant \\
N S\left(s_{g}\right) \sum_{i^{\prime}=0}^{g} p_{i j, i^{\prime}}^{k}-N S\left(s_{0}\right) \sum_{i^{\prime}=0}^{g} p_{i j, i^{\prime}}^{k^{\prime}}= \\
N S\left(s_{g}\right)-N S\left(s_{0}\right) .
\end{gathered}
$$

Then there is $\min S M_{i j}^{k k^{\prime}}=1-\frac{N S\left(s_{g}\right)-N S\left(s_{0}\right)}{N S\left(s_{g}\right)-N S\left(s_{0}\right)}=0$. Thus, we have $0 \leqslant S M_{i j}^{k k^{\prime}} \leqslant 1$. Similarly, we can prove the situation when $\sum_{i^{\prime}=0}^{g} N S\left(s_{i}^{\prime}\right) p_{i j, i^{\prime}}^{k}-\sum_{i^{\prime}=0}^{g} N S\left(s_{i}^{\prime}\right) p_{i j, i^{\prime}}^{k^{\prime}} \leqslant$ 0 .

(ii) Based on Definition 6, we have

$$
\begin{gathered}
S M_{i j}^{k k^{\prime}}=1-\frac{1}{N S\left(s_{g}\right)-N S\left(s_{0}\right)} \mid \sum_{i^{\prime}=0}^{g} N S\left(s_{i}^{\prime}\right) p_{i j, i^{\prime}}^{k}- \\
\sum_{i^{\prime}=0}^{g} N S\left(s_{i^{\prime}}\right) p_{i j, i^{\prime}}^{k^{\prime}} \mid= \\
1-\frac{1}{N S\left(s_{g}\right)-N S\left(s_{0}\right)} \mid \sum_{i^{\prime}=0}^{g} N S\left(s_{i}^{\prime}\right) p_{i j, i^{\prime}}^{k^{\prime}}-
\end{gathered}
$$

$$
\sum_{i^{\prime}=0}^{g} N S\left(s_{i^{\prime}}\right) p_{i j, i^{\prime}}^{k} \mid=S M_{i j}^{k^{\prime} k}
$$

then the second property is proven as well.

(iii) When $p_{i j, i^{\prime}}^{k}=p_{i j, i^{\prime}}^{k^{\prime}}$, we have

$$
S M_{i j}^{k k^{\prime}}=1-\frac{\left|\sum_{i^{\prime}=0}^{g} N S\left(s_{i^{\prime}}\right)\left(p_{i j, i^{\prime}}^{k}-p_{i j, i^{\prime}}^{k^{\prime}}\right)\right|}{N S\left(s_{g}\right)-N S\left(s_{0}\right)}=1 .
$$

have

(iv) When $P_{i j}^{k}=\left\{\left(s_{i j, 0}^{k}, 1\right)\right\}, P_{i j}^{k^{\prime}}=\left\{\left(s_{i j, g}^{k^{\prime}}, 1\right)\right\}$, we

$$
S M_{i j}^{k k^{\prime}}=1-\frac{\left|N S\left(s_{0}\right)(1-0)+N S\left(s_{g}\right)(0-1)\right|}{N S\left(s_{g}\right)-N S\left(s_{0}\right)}=0 .
$$

When $P_{i j}^{k}=\left\{\left(s_{i j, g}^{k}, 1\right)\right\}$ and $P_{i j}^{k^{\prime}}=\left\{\left(s_{i j, 0}^{k^{\prime}}, 1\right)\right\}$, we have $S M_{i j}^{k k^{\prime}}=1-\frac{\left|N S\left(s_{0}\right)(0-1)+N S\left(s_{g}\right)(1-0)\right|}{N S\left(s_{g}\right)-N S\left(s_{0}\right)}=0$.

Thus, Corollary 1 is proven here.

Let $S M_{i j}^{k}$ be the degree of group similarity of the expert $e^{k}$ on the alternative $a_{i}$ with respect to the attribute $c_{j}$, then it is obtained as

$$
S M_{i j}^{k}=\frac{1}{K-1} \sum_{k=1, k^{\prime} \neq k}^{K} S M_{i j}^{k k^{\prime}} .
$$

Definition 7 Suppose the degree of group similarity between two experts is $S M_{i j}^{k k^{\prime}}$, then the comprehensive degree of group similarity is defined as

$$
S M=\frac{1}{M N K(K-1)} \sum_{i=1}^{M} \sum_{j=1}^{N} \sum_{k=1}^{K} \sum_{k^{\prime}=1, k^{\prime} \neq k}^{K} S M_{i j}^{k k^{\prime}},
$$

and the degree of group similarity on the alternative $a_{i}$ is expressed as

$$
S M_{i}=\frac{1}{N K(K-1)} \sum_{j=1}^{N} \sum_{k=1}^{K} \sum_{k^{\prime}=1, k^{\prime} \neq k}^{K} S M_{i j}^{k k^{\prime}} .
$$

In (7), (8) and (9), the key work is to obtain the numerical scale of each linguistic term. In the literature, the approaches on this issue are mainly classified into four categories: (i) The method of extension principle [12], where the membership function should be subjectively provided, which is often unscientific due to a lack of information. (ii) The symbol transferring method [42], whose limitation is that some information may be lost as the linguistic terms are approximately replaced by discrete values. (iii) The 2-tuple linguistic method [43], which can only deal with a uniformly and symmetrically distributed linguistic terms set. (iv) The linguistic granulation optimization method [44], which can solve the problem when the linguistic terms are uneven in each interval but also can reduce the information loss during the transformation 
process. However, this method needs a complex calculation process in which the segmentation points should be determined. To make up for these limitations, the combination of the symbol transferring method and the linguistic granulation optimization method is a good way to get the linguistic scales. Based on the idea in [42], suppose the intervals that each linguistic term lies in are $[0,0.5),[0.5,1.5), \ldots,[g-1.5, g-0.5),[g-0.5, g]$, i.e., $s_{0} \in[0,0.5), \ldots, s_{g} \in[g-0.5, g]$. Then, a linguistic granulation optimization approach is proposed to determine the values of $N S\left(s_{i^{\prime}}\right)\left(i^{\prime}=0,1, \ldots, g\right)$. The method not only simplifies the optimization process but also reduces the information loss.

In the work, the values of linguistic terms are determined by maximizing the degree of group similarity under some constraints. The aim is for decision-making reliability to have a larger degree of differentiation and thus to enhance the acceptability of the decision-making result. Thus, a nonlinear programming (NLP 1) is then put forward as

$$
\begin{gathered}
\max S M=\frac{1}{M N K(K-1)} \sum_{i=1}^{M} \sum_{j=1}^{N} \sum_{k=1}^{K} \sum_{k^{\prime}=1, k^{\prime} \neq k}^{K} S M_{i j}^{k k^{\prime}} \\
\text { s.t. } 0 \leqslant N S\left(s_{0}\right) \leqslant 0.5 \\
i^{\prime}-0.5 \leqslant N S\left(s_{i}^{\prime}\right) \leqslant i^{\prime}+0.5, \quad i^{\prime}=1,2, \ldots, g-1 \\
g-0.5 \leqslant N S\left(s_{g}\right) \leqslant g \\
N S\left(s_{i^{\prime}+1}\right)-N S\left(s_{i^{\prime}}\right) \geqslant \delta, \quad i^{\prime}=0,1, \ldots, g-1 \text {. }
\end{gathered}
$$

In NLP 1, (11)-(13) denote the intervals that the numerical scales of linguistic terms belong to; (14) is set to ensure unequal utilities of two adjacent grades, where $\delta$ is often subjectively given according to the real situation. Thus, using NLP $1, N S\left(s_{i^{\prime}}\right)\left(i^{\prime}=0,1, \ldots, g\right)$ is obtained.

Theorem 1 An optimal solution exists in NLP 1.

Proof Let the feasible region of NLP 1 be denoted as $\Omega_{1}$. It is not difficult to find that the constraints in $\Omega_{1}$ are bounded and $\Omega_{1}$ is non-empty. Thus, $\Omega_{1}$ is a non-empty and bounded closed region. Moreover, it is obvious that the objective function of NLP 1 is a continuous function on region $\Omega_{1}$. Thus, the objective function must attain a maximum according to the extreme value theorem of multivariate functions [45]. Therefore, the optimal solution does exist in NLP 1.

\subsubsection{An approach to measure the degree of certainty}

In practice, more hesitance of experts means higher uncertainty involved in the information, and thus the information reliability of the experts is comparatively lower. In the evidence theory, this kind of uncertainty is measured by the nonspecificity or amount of uncertainty [30] which can be respectively obtained based on Definitions 3 and 4. Then, based on the nonspecificity or the amount of uncertainty, the proposed method uses the degree of certainty to measure the information reliability of experts.

Hartley measure is a good way to measure the nonspecificity without probabilities (see Definition 3), but it is not normalized and cannot directly be compared or combined with the degree of group similarity.

Definition 8 Suppose there are $g+1$ linguistic terms in a linguistic set, then the degree of certainty is defined as

$$
D C=1-\log _{g+1}(|A|) .
$$

Theorem $2 D C$ lies in the interval $[0,1]$.

Proof Based on Definition 3, we have $H(A)=$ $\log _{2}(|A|)$. Because of $1 \leqslant|A| \leqslant g+1, \max H(A)=$ $\log _{2}(g+1)$ and $\min H(A)=0, \log _{2}(|A|) / \log _{2}(g+1)$ lies in the range $[0,1]$. Moreover, because of $D C=$ $1-\log _{g+1}(|A|)=1-\log _{2}(|A|) / \log _{2}(g+1)$, we have $D C \in[0,1]$.

When $|A|=1$, there is $\max D C=1$, that means the expert information has full degree of certainty; when $|A|=g+1$, there is $\min D C=0$, and the expert information has full degree of uncertainty. Moreover, though $D C$ is normalized into the range $[0,1]$, it does not change the original meaning of $H(A)$. Fig. 2 shows that the growing trend of $\log _{g+1}(|A|)$ with increasing $|A|$ is the same as that of $\log _{2}(|A|)$. Thus, it is reasonable to define the degree of certainty.

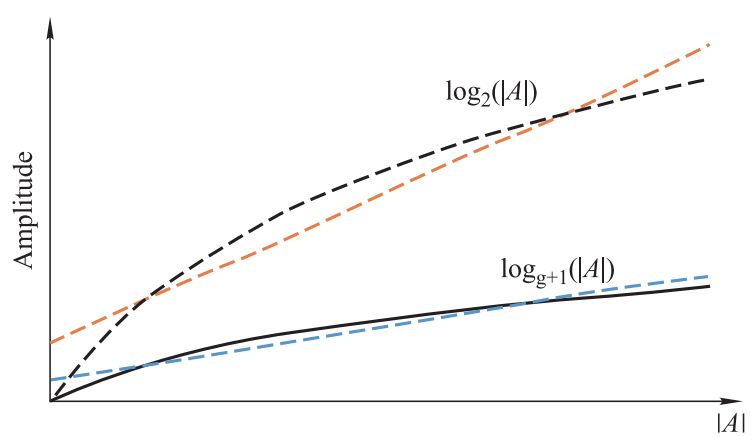

Fig. 2 Impact of $|A|$ on $\log _{2}(|A|)$ and $\log _{g+1}(|A|)$

Suppose $\left|A_{i j}^{k l}\right|$ is the cardinality of the HFLTS $h_{i j}^{k l}$, then the degree of certainty of the expert $e^{k}$ on the alternative $a_{i}$ with respect to the attribute $c_{j}$ is obtained as

$$
D C_{i j}^{k}=1-D U_{i j}^{k}=1-\frac{1}{L} \sum_{l=1}^{L} \log _{g+1}\left(\left|A_{i j}^{k l}\right|\right)_{A_{i j}^{k l} \in S} .
$$

Then the expert reliability is measured from perspectives of the degree of group similarity and degree of certainty. 
Definition 9 Let $S M_{i j}^{k}$ and $D C_{i j}^{k}$ respectively be the degree of group similarity and degree of certainty of the expert $e^{k}$ on the alternative $a_{i}$ with respect to the attribute $c_{j}$, then its corresponding expert reliability is defined as

$$
R_{i j}^{k}=\alpha S M_{i j}^{k}+(1-\alpha) D C_{i j}^{k}
$$

where $\alpha$ is a preference coefficient that is determined according to the real situation, and $\alpha \in[0,1]$.

The weight of experts is mainly to characterize the relative importance of one expert in comparison with others; while the reliability of one expert indicates his or her inherent property, it is defined as the degree to which the assessment of an alternative on the attribute is consistent with the real performance of the alternative [22]. Thus, the information reliability of experts should be considered in the aggregation process besides their weight. In order to effectively combine these two aspects, Yang [46] proposed a hybrid method as follows.

Definition 10 [46] Suppose the expert weight is $\lambda^{k}\left(\sum_{k=1}^{K} \lambda^{k}=1\right)$, and the expert reliability is $R_{i j}^{k}$, then the hybrid weight of one expert is defined as

$$
w_{i j}^{k}=\frac{\lambda^{k}}{1+\lambda^{k}-R_{i j}^{k}} .
$$

In (18), $\sum_{k=1}^{K} w_{i j}^{k}$ may not be equal to 1 , so $w_{i j}^{k}$ should be normalized to ensure $\sum_{k=1}^{K} w_{i j}^{k}=1$. Thus, the normalized weight of each expert is expressed by

$$
\hat{w}_{i j}^{k}=w_{i j}^{k} / \sum_{k=1}^{K} w_{i j}^{k}
$$

where $\sum_{k=1}^{K} \hat{w}_{i j}^{k}=1$.

According to (5), we have the probability $p_{i j, i^{\prime}}^{k}$, then the aggregated probability of the linguistic term $s_{i^{\prime}}$ on the alternative $a_{i}$ with respect to the attribute $c_{j}$ is denoted by

$$
p_{i j, i^{\prime}}=\sum_{k=1}^{K} \hat{w}_{i j}^{k} p_{i j, i^{\prime}}^{k}=\sum_{k=1}^{K} w_{i j}^{k} p_{i j, i^{\prime}}^{k} / \sum_{k=1}^{K} w_{i j}^{k}
$$

where $p_{i j, i^{\prime}} \in[0,1]$.

Thus, we get the ordered proportional linguistic pairs

$$
\begin{aligned}
P_{H_{s}}^{\prime}= & \left\{\left(s_{i j, i^{\prime}}, p_{i j, i^{\prime}}\right) \mid s_{i j, i^{\prime}} \in S, i=1,2 \ldots, M ;\right. \\
& \left.j=1,2, \ldots, N ; i^{\prime}=0,1, \ldots, g\right\} .
\end{aligned}
$$

Theorem 3 There must be $\sum_{i^{\prime}=0}^{g} p_{i j, i^{\prime}}=1$.

Proof It is known that $\sum_{k=1}^{K} \hat{w}_{i j}^{k}=1, \sum_{i^{\prime}=0}^{g} p_{i j, i^{\prime}}^{k}=1$, then there is

$$
\begin{aligned}
& \sum_{i^{\prime}=0}^{g} p_{i j, i^{\prime}}=\sum_{i^{\prime}=0}^{g} \sum_{k=1}^{K} \hat{w}_{i j}^{k} p_{i j, i^{\prime}}^{k}= \\
& \sum_{k=1}^{K} \hat{w}_{i j}^{k} \sum_{i^{\prime}=0}^{g} p_{i j, i^{\prime}}^{k}=\sum_{k=1}^{K} \hat{w}_{i j}^{k}=1 .
\end{aligned}
$$

\subsection{Generation of attribute reliability}

In dynamic decision-makings, a better performance stability of one alternative with respect to one attribute means a better predictability and controllability on the future performance of the alternative, and thus a higher degree of certainty can be held by decision-makers during the decisionmaking process. In $P_{H_{s}}^{\prime}$, when the linguistic probabilities of one alternative with respect to the relevant attribute are widely dispersed, there exists a higher degree of uncertainty and thus a poorer stability. Thus, the degree of stability can be measured based on the amount of uncertainty.

Using (20), the aggregated probability $p_{i j, i^{\prime}}$ is obtained $\left(p_{i j, i^{\prime}} \in[0,1]\right)$, and according to Definition 4 , a model to determine the amount of uncertainty is developed as

$$
\begin{gathered}
A U_{i j}=\max \left[-\sum_{i^{\prime}=0}^{g} p_{i j, i^{\prime}}^{\prime} \log _{2} p_{i j, i^{\prime}}^{\prime}\right] \\
\text { s. t. } p_{i j, i^{\prime}}^{\prime} \in[0,1], \quad \sum_{i^{\prime}=0}^{g} p_{i j, i^{\prime}}^{\prime}=1 \\
p_{i j, i^{\prime}} \leqslant p_{i j, i^{\prime}}^{\prime} \leqslant 1-\sum_{i^{\prime}{ }_{1}=0}^{g} p_{i j, i^{\prime}{ }_{1}}+p_{i j, i^{\prime}}
\end{gathered}
$$

where $p_{i j, i^{\prime}}^{\prime}$ is the new optimized probability.

Theorem $4 p_{i j, i^{\prime}}$ is the optimum solution of the model, and there is $A U_{i j}=-\sum_{i^{\prime}=0}^{g} p_{i j, i^{\prime}} \log _{2} p_{i j, i^{\prime}}$.

Proof In the work, we have $\sum_{i^{\prime}=0}^{g} p_{i j, i^{\prime}}=1$ (see Theorem 3) and $p_{i j, i^{\prime}} \in[0,1]$. Then there are $p_{i j, i^{\prime}}=$ $1-\sum_{i^{\prime} 1=0}^{g} p_{i j, i^{\prime} 1}+p_{i j, i^{\prime}}$, and $p_{i j, i^{\prime}} \leqslant p_{i j, i^{\prime}}^{\prime} \leqslant p_{i j, i^{\prime}}$, so we have $p_{i j, i^{\prime}}^{\prime}=p_{i j, i^{\prime}}$. Thus, $p_{i j, i^{\prime}}$ is an optimum solution of the model. Then we have $A U_{i j}=-\sum_{i^{\prime}=0}^{g} p_{i j, i^{\prime}} \log _{2} p_{i j, i^{\prime}}$. 
In order to clearly measure the stability of one alternative with respect to each attribute, we provide a definition as follows.

Definition 11 Suppose $A U_{i j}$ denotes the amount of uncertainty of the alternative $a_{i}$ with respect to the attribute $c_{j}$, then the degree of stability is defined as

$$
D S_{i j}=1-\frac{A U_{i j}}{\log _{2}(g+1)} .
$$

Theorem $5 \quad D S_{i j}$ belongs to the range of $[0,1]$.

Proof We know that $A U_{i j}=-\sum_{i^{\prime}=0}^{g} p_{i j, i^{\prime}} \log _{2} p_{i j, i^{\prime}}$.

As is known that

$$
\begin{gathered}
p_{i j, i^{\prime}} \in[0,1] \Rightarrow \log _{2} p_{i j, i^{\prime}} \leqslant 0 \\
\Rightarrow A U_{i j}=-\sum_{i^{\prime}=0}^{g} p_{i j, i^{\prime}} \log _{2} p_{i j, i^{\prime}} \geqslant 0 .
\end{gathered}
$$

Hence, the lower bound of $A U_{i j}$ is zero.

Because of $\sum_{i^{\prime}=0}^{g} p_{i j, i^{\prime}}=1$, we can create the Lagrangian function as follows:

$$
f\left(p_{i j, i^{\prime}}\right)=-\sum_{i^{\prime}=0}^{g} p_{i j, i^{\prime}} \log _{2} p_{i j, i^{\prime}}+\lambda \cdot\left(\sum_{i^{\prime}=0}^{g} p_{i j, i^{\prime}}-1\right)
$$

where $\lambda$ is the Lagrangian variable. In order to obtain the extrema of the function, we take

$$
\begin{gathered}
\frac{\partial f\left(p_{i j, i^{\prime}}\right)}{\partial p_{i j, i^{\prime}}}=-\log _{2} p_{i j, i^{\prime}}-\frac{1}{\ln 2}+\lambda=0, \\
\frac{\partial f\left(p_{i j, i^{\prime}}\right)}{\partial \lambda}=\sum_{i^{\prime}=0}^{g} p_{i j, i^{\prime}}-1=0, \\
\Rightarrow p_{i j, i^{\prime}}=2^{\lambda-\frac{1}{\ln 2}}=c, \quad \sum_{i^{\prime}=0}^{g} p_{i j, i^{\prime}}=1 .
\end{gathered}
$$

Obviously, $c$ is a constant, then there is $\sum_{i^{\prime}=0}^{g} c=1$, so we have $c=1 /(g+1)$.

The second-order derivative is then calculated to know whether the extrema is a maximum or a minimum, we have

$$
\begin{gathered}
\frac{\partial^{2} f\left(p_{i j, i^{\prime}}\right)}{\partial\left(p_{i j, i^{\prime}}\right)^{2}}=-\frac{1}{p_{i j, i^{\prime}} \ln 2} \log _{2} p_{i j, i^{\prime}} \leqslant 0, \\
\frac{\partial^{2} f\left(p_{i j, i^{\prime}}\right)}{\partial(\lambda)^{2}}=0 .
\end{gathered}
$$

Hence, $A U_{i j}$ is a convex function and the extrema is the maximum, i.e., $\max A U_{i j}=\log _{2}(g+1)$.
Then, the range of $A U_{i j}$ is $\left[0, \log _{2}(g+1)\right]$, so we have

$$
\begin{gathered}
\min D S_{i j}=1-\log _{2}(g+1) / \log _{2}(g+1)=0, \\
\max D S_{i j}=1-0 / \log _{2}(g+1)=1 .
\end{gathered}
$$

Thus, Theorem 5 is proven here.

In the work, group conflict is mainly brought by experts, so there is no need to consider the group similarity on attributes. As mentioned in the paper, the degree of certainty can be considered as a measure of the reliability. Similarly, the degree of stability which is also measured by the uncertainty is used as a measure of the reliability, thus, we have

$$
R_{i j}^{\prime}=D S_{i j}=1-\frac{A U_{i j}}{\log _{2}(g+1)} .
$$

Suppose the weight of each attribute is $w_{j}$, then according to the idea of Definition 10, the hybrid weight of each attribute is expressed by

$$
w_{i j}=\frac{w_{j}}{1+w_{j}-R_{i j}^{\prime}} .
$$

Then the normalized hybrid weight of one attribute is obtained as

$$
\hat{w}_{i j}=w_{i j} / \sum_{j=1}^{N} w_{i j}
$$

where $\sum_{j=1}^{N} \hat{w}_{i j}=1$.

The probability $p_{i j, i^{\prime}}$ is obtained by using (20), then the aggregated probability of the linguistic term $s_{i^{\prime}}$ on the alternative $a_{i}$ is generated as

$$
p_{i, i^{\prime}}=\sum_{j=1}^{N} \hat{w}_{i j} p_{i j, i^{\prime}}=\frac{\sum_{j=1}^{N} w_{i j} p_{i j, i^{\prime}}}{\sum_{j=1}^{N} w_{i j}}
$$

where $p_{i, i^{\prime}} \in[0,1]$.

Thus, we get the ordered proportional linguistic pairs

$$
\begin{gathered}
P_{H_{s}}^{\prime \prime}=\left\{\left(s_{i, i^{\prime}}, p_{i, i^{\prime}}\right) \mid s_{i, i^{\prime}} \in S,\right. \\
\left.i=1,2 \ldots, M ; i^{\prime}=0,1, \ldots, g\right\} .
\end{gathered}
$$

\subsection{Selection among alternatives}

Based on Definition 2, the comprehensive expectation of each alternative is obtained as

$$
E_{i}=\sum_{i^{\prime}=0}^{g} p_{i, i^{\prime}} N S\left(s_{i^{\prime}}\right)
$$


and the degree of stability is obtained as

$$
D S_{i}=1-\frac{A U_{i}}{\log _{2}(g+1)}=1+\frac{\sum_{i^{\prime}=0}^{g} p_{i, i^{\prime}} \log _{2} p_{i, i^{\prime}}}{\log _{2}(g+1)} .
$$

For the alternatives $a_{i}$ and $a_{v}(i=1,2, \ldots, M ; v=$ $1,2, \ldots, M$, and $i \neq v$ ), if $E_{i}>E_{v}$, there is $a_{i} \succ a_{v}$; if $E_{i}<E_{v}$, there is $a_{i} \prec a_{v}$; if $E_{i}=E_{v}$, we should further consider the degree of stability to get a correct ranking order. Generally, if one alternative has a more stable development than that of others, its relevant reliability is comparatively higher, helping to reduce the decision-making risk. Based on this idea, when $E_{i}=E_{v}$, there are three situations: (i) if $D S_{i}>D S_{v}, a_{i} \succ a_{v}$; (ii) if $D S_{i}<D S_{v}$, $a_{i} \prec a_{v}$; (iii) if $D S_{i}=D S_{v}, a_{i} \Leftrightarrow a_{v}$.

For example, suppose a linguistic terms set is $S=$ $\left\{s_{0}, s_{1}, s_{2}, s_{3}, s_{4}\right\}$, where $N S\left(s_{0}\right)=0, N S\left(s_{1}\right)=1$, $N S\left(s_{2}\right)=2, N S\left(s_{3}\right)=3, N S\left(s_{4}\right)=4$. The proportional linguistic pairs of two alternatives $\left(a_{1}\right.$ and $\left.a_{2}\right)$ are

$$
\begin{gathered}
P_{1}=\left\{\left(s_{0}, 0\right),\left(s_{1}, 0\right),\left(s_{2}, 0\right),\left(s_{3}, 1\right),\left(s_{4}, 0\right)\right\}, \\
P_{2}=\left\{\left(s_{0}, 0\right),\left(s_{1}, 0\right),\left(s_{2}, 0.15\right),\left(s_{3}, 0.7\right),\left(s_{4}, 0.15\right)\right\} .
\end{gathered}
$$

The comprehensive assessments of two alternatives are $E_{1}=3, E_{2}=3$, so there is $E_{1}=E_{2}$. Then according to (29), we have $D S_{1}=1, D S_{2}=0.49$, so we have $D S_{1}>D S_{2}$. Thus, $a_{1} \succ a_{2}$ is obtained.

Comprehensively, the steps of the proposed method in the work are outlined as follows.

Step 1 Form a DHFLGDM problem. $K$ experts are selected to give their hesitant linguistic information $h_{i j}^{k l}$ on $M$ alternatives with respect to $N$ attributes at $L$ stages, where $h_{i j}^{k l} \in S, S=\left\{s_{0}, s_{1}, \ldots, s_{g}\right\}$.

Step 2 Generate the probability distribution based on the DHFLTSs. By using (5), a group of ordered proportional linguistic pairs are obtained as $P_{H_{s}}=$ $\left\{\left(s_{i j, i^{\prime}}^{k}, p_{i j, i^{\prime}}^{k}\right) \mid s_{i j, i^{\prime}}^{k} \in S, i=1,2 \ldots, M ; j=\right.$ $\left.1,2, \ldots, N ; k=1,2, \ldots, K ; i^{\prime}=0,1, \ldots, g\right\}$ (Equation (6) can be used if it is a static situation).

Step 3 Aggregate the information of experts. Based on (7) - (9) and NLP 1, the degree of group similarity of each expert is obtained. Then, through (16), the degree of certainty is computed as well. Based on these two aspects, information reliability of experts is generated through (17). Then, (18) is used to calculate the hybrid weight and thus we get the aggregated proportional linguistic pair $P_{H_{s}}^{\prime}$ by using (19) and (20).

Step 4 Aggregate the information of attributes. Equations (19) and (20) are used to get the reliability of alternatives on each attribute. Then the ordered proportional linguistic pair $P_{H_{s}}^{\prime \prime}$ is obtained by using (25) - (27).
Step 5 Make a selection among alternatives. According to the approach proposed in Section 3.4, the ranking order of alternatives is generated as a solution of the DHFLGDM problem with the reliability being included.

\section{Experimental results}

In this section, we utilize one case to demonstrate the feasibility and rationality of the proposed method, and the proposed method is compared with three existing methods to express advantages of the proposed method.

\subsection{A real-world example}

The aircraft manufacturing industry plays a significant role in the national defense, economic growth, and promotion of the civil aviation industry. In practice, the industry is mainly manifested as the "main manufacturer - suppliers" production mode. The main manufacturer is the production organizer, and the suppliers are its key partners who play an important role in the successful production of an aircraft. For example, Boeing, a leading company in the global aerospace industry, has 545 component suppliers from more than 70 countries, and all these suppliers are selected through a strict selection process in order to produce safe and competitive aircraft. Therefore, the selection of suppliers has great significance for the large aircraft manufacturer. In China, the development of the C919 aircraft marks that the aircraft industry in the country has entered a new development era, and thus the selection of suppliers will be even more important. The principal systems of an aircraft are flight control, fuel, hydraulics, electrical, environmental control, emergency, air power, avionics, and engine, et al. These systems have particularly strict requirements for the suppliers, and the selection is not a short process in order to make a comprehensive evaluation for them. Hence, a comprehensive and dynamic evaluation is necessary for the selection process. Among those systems, the avionics system occupies an extremely important position in the large aircraft project. It must meet the stringent reliability and safety requirements and plays a greatly important role in one aircraft [47]. Therefore, the requirements for suppliers of avionics systems are very high, and the dynamic selection process is necessarily in demand.

In the case, there are only a small number of potential candidate suppliers that can satisfy the initial requirements. After a preliminary comparison, three suppliers are selected as the potential candidates (denoted by $a_{1}, a_{2}$ and $\left.a_{3}\right)$. In the survey, the selection indices mainly involve three aspects: design and manufacturing capability, financial capability, and cooperative service capability (denoted by $c_{1}, c_{2}$ and $c_{3}$ ). $c_{1}$ mainly refers to the supplier's quality level, development capability, and schedule management ability, reflecting the hardware quality of the avionics system. $c_{2}$ reflects the ability of suppliers. $c_{3}$ reflects the ser- 
vice capability and responsiveness to the customer's demands, including the response time, the coordination of emergency deliveries, the training level for the main manufacturer and their customers, and so on. Each of these indices involves many sub-aspects which are difficult to be expressed in terms of accurate or uncertain values. In reality, the experts from the relevant departments can provide their opinions with DHFLTSs. Therefore, the case belongs to a DHFLGDM problem, it is reasonable to adopt the proposed method to solve this case.

The industry allocates attribute weight as follows: $c_{1}$ generally accounts for $35 \%, c_{2}$ accounts for $35 \%$, and $c_{3}$ accounts for $30 \%$. Because the production of large aircraft avionics systems requires a long time, the manufacturer needs to conduct research considering possible, dynamic changes in the market. Therefore, the selection committee selects data from the last four years as a basis for the decision-making. In the case, three experts $\left(e^{k}, k=\right.$ $1,2,3)$ from relevant departments of the industry help to evaluate the three suppliers, who are assumed to have equal importance relative to each other. Suppose a set of grades is $S=\left\{s_{0}=\right.$ extremely bad, $s_{1}=$ worse, $s_{2}=$ bad, $s_{3}=$ medium, $s_{4}=\operatorname{good}, s_{5}=$ better, $s_{6}=$ excellent $\}$, and the DHFLTSs that are given by experts are shown in Table 1.

Table 1 Evaluation matrix of experts

\begin{tabular}{|c|c|c|c|c|c|c|c|c|c|c|}
\hline \multirow{2}{*}{ Stage } & \multirow{2}{*}{ Alternative } & \multicolumn{3}{|c|}{ Design and manufacturing capability $c_{1}$} & \multicolumn{3}{|c|}{ Financial capability $c_{2}$} & \multicolumn{3}{|c|}{ Cooperative service capability $c_{3}$} \\
\hline & & $e^{1}$ & $e^{2}$ & $e^{3}$ & $e^{1}$ & $e^{2}$ & $e^{3}$ & $e^{1}$ & $e^{2}$ & $e^{3}$ \\
\hline \multirow{3}{*}{$t_{1}$} & $a_{1}$ & $s_{4}$ & $s_{4}$ & $\left(s_{3}, s_{4}\right)$ & $s_{4}$ & $\left(s_{4}, s_{5}\right)$ & $s_{4}$ & $s_{5}$ & $\left(s_{4}, s_{5}\right)$ & $s_{4}$ \\
\hline & $a_{2}$ & $s_{4}$ & $s_{4}$ & $s_{3}$ & $s_{4}$ & $s_{4}$ & $\left(s_{3}, s_{4}\right)$ & $\left(s_{4}, s_{5}\right)$ & $s_{4}$ & $s_{4}$ \\
\hline & $a_{3}$ & $\left(s_{3}, s_{4}\right)$ & $s_{4}$ & $s_{3}$ & $s_{4}$ & $s_{4}$ & $\left(s_{3}, s_{4}\right)$ & $s_{4}$ & $s_{4}$ & $\left(s_{3}, s_{4}\right)$ \\
\hline \multirow[b]{2}{*}{$t_{2}$} & $a_{1}$ & $\left(s_{4}, s_{5}\right)$ & $\left(s_{4}, s_{5}\right)$ & $s_{4}$ & $s_{5}$ & $s_{5}$ & $s_{4}$ & $s_{5}$ & $s_{5}$ & $s_{4}$ \\
\hline & $a_{2}$ & $s_{4}$ & $\left(s_{4}, s_{5}\right)$ & $s_{4}$ & $s_{5}$ & $s_{5}$ & $\left(s_{4}, s_{5}\right)$ & $\left(s_{4}, s_{5}\right)$ & $s_{5}$ & $s_{4}$ \\
\hline \multirow{3}{*}{$t_{3}$} & $\overline{a_{1}}$ & $\left(s_{4}, s_{5}\right)$ & $s_{5}$ & $s_{4}$ & $s_{5}$ & $\left(s_{5}, s_{6}\right)$ & $s_{4}$ & $s_{5}$ & $s_{5}$ & $s_{4}$ \\
\hline & $a_{2}$ & $s_{5}$ & $s_{5}$ & $\left(s_{4}, s_{5}\right)$ & $\left(s_{4}, s_{5}\right)$ & $\left(s_{5}, s_{6}\right)$ & $s_{4}$ & $\left(s_{5}, s_{6}\right)$ & $s_{5}$ & $\left(s_{4}, s_{5}\right)$ \\
\hline & $a_{3}$ & $s_{4}$ & $\left(s_{4}, s_{5}\right)$ & $\left(s_{3}, s_{4}\right)$ & $\left(s_{5}, s_{6}\right)$ & $s_{5}$ & $s_{4}$ & $s_{5}$ & $s_{5}$ & $\left(s_{3}, s_{4}\right)$ \\
\hline \multirow{3}{*}{$t_{4}$} & $a_{1}$ & $s_{5}$ & $s_{5}$ & $\left(s_{3}, s_{4}\right)$ & $\left(s_{5}, s_{6}\right)$ & $\left(s_{5}, s_{6}\right)$ & $\left(s_{4}, s_{5}\right)$ & $s_{5}$ & $s_{5}$ & $s_{4}$ \\
\hline & $a_{2}$ & $s_{5}$ & $s_{5}$ & $s_{4}$ & $\left(s_{5}, s_{6}\right)$ & $\left(s_{5}, s_{6}\right)$ & $s_{5}$ & $\left(s_{5}, s_{6}\right)$ & $s_{5}$ & $\left(s_{4}, s_{5}\right)$ \\
\hline & $a_{3}$ & $s_{4}$ & $s_{5}$ & $\left(s_{3}, s_{4}\right)$ & $\left(s_{5}, s_{6}\right)$ & $s_{5}$ & $s_{5}$ & $s_{5}$ & $s_{5}$ & $s_{4}$ \\
\hline
\end{tabular}

(i) Calculation process and result analysis

Based on the proposed method in the work, the case is analyzed by the following steps.

Step 1-2 The linguistic terms are first transformed into the corresponding probability distributions by using (5). Through solving NLP 1 , we get $N S\left(s_{0}\right)=0, N S\left(s_{1}\right)=$ $1, N S\left(s_{2}\right)=1.5, N S\left(s_{3}\right)=3.5, N S\left(s_{4}\right)=4$, $N S\left(s_{5}\right)=4.5, N S\left(s_{6}\right)=5.5$. Then, the degree of group similarity of each alternative is obtained as $S M_{1}=0.963$, $S M_{2}=0.974, S M_{3}=0.966$ by using (10). In this case, the weight of experts is denoted by $\lambda=\{1 / 3,1 / 3,1 / 3\}$. By computing the degree of group similarity $S M_{i j}^{k}(8)$ and degree of certainty $D C_{i j}^{k}(16)$, the reliability and hybrid weight of experts are successively generated as $R_{i j}^{k}$ (17) and $\hat{w}_{i j}^{k}$ (19), and without the loss of generality, suppose that $\alpha=0.5$. Then the probability distribution $p_{i j, i^{\prime}}$ of grades of each alternative with respect to each attribute is obtained by applying (20).

Step 3 As mentioned above, the prior weight of attributes is given as $w=\{0.35,0.35,0.3\}$. By calculating the degree of certainty of each alternative with respect to each attribute, the attribute reliability $R_{i j}$ is obtained and thus $\hat{w}_{i j}$ is known by using (24) and (26). Then, the probability distribution $p_{i, i^{\prime}}$ of grades with respect to each alter- native is obtained in Table 2 through (27).

Step 4 To rank the alternatives, the comprehensive assessment value $E_{i}$ of each alternative should be calculated through (28), i.e., $E_{1}=4.28, E_{2}=4.32, E_{3}=4.1$. Moreover, by using (29), $D S_{1}=0.51, D S_{2}=0.53$, $D S_{3}=0.58$ are obtained as well. Because both $E_{3}$ and $D S_{3}$ are comparatively smaller than those of other two suppliers, the supplier $a_{3}$ ranks the last place. For the supplier $a_{2}, E_{2}$ is of the largest value among three alternatives, and $D S_{2}$ is almost the same as that of the supplier $a_{1}$, so it should be ranked in the first place. Then we have the good reason to get the ranking order, which is $a_{2} \succ a_{1} \succ a_{3}$. Thus, $a_{2}$ should be selected to be the partner to provide the avionics system.

Table 2 Values of $\boldsymbol{p}_{i, i^{\prime}}$

\begin{tabular}{cccccccc}
\hline Alternative & $s_{0}$ & $s_{1}$ & $s_{2}$ & $s_{3}$ & $s_{4}$ & $s_{5}$ & $s_{6}$ \\
\hline$a_{1}$ & 0 & 0 & 0 & 0.1 & 0.59 & 0.31 & 0 \\
$a_{2}$ & 0 & 0 & 0 & 0 & 0.4 & 0.45 & 0.15 \\
$a_{3}$ & 0 & 0 & 0 & 0 & 0.4 & 0.6 & 0 \\
\hline
\end{tabular}

(ii) Method comparison

In order to further illustrate the advantages and the necessity of our conceptual extension in the study, a comparison with three existing methods respectively in [18], 
[28], [36] is made in the work; the results are presented in Table 3(as the methods in [18] and [28] cannot solve the dynamic information, the results in the table are the simple unweighted average values of four years).

Seen from Table 3, the degree of group similarity which is obtained by the proposed method is generally larger than that from other three methods, demonstrating the necessity of NLP 1 . As for the ranking order, the result obtained by our approach is the same as that from Chen's method [18] and Wu's method, demonstrating the rationality and feasibility of the proposed method. However, the best and worst alternatives obtained by Wang's method [36] are $a_{3}$ and $a_{2}$, whereas those are $a_{2}$ and $a_{3}$ by using our method. Obviously, the ranking places of these two alternatives are opposite. The differences in Table 4 explain the different ranking orders of the two methods.

Table 3 Results of different methods

\begin{tabular}{ccc}
\hline Method & Group similarity & Ranking order \\
\hline \multirow{3}{*}{ Chen's method [18] } & $S M_{1}=0.943$ & \\
& $S M_{2}=0.961$ & $a_{2} \succ a_{1} \succ a_{3}$ \\
& $S M_{3}=0.931$ & \\
\hline \multirow{3}{*}{ Wang's method [36] } & $S M_{1}=0.95$ & \\
& $S M_{2}=0.951$ & $a_{3} \succ a_{1} \succ a_{2}$ \\
& $S M_{3}=0.9$ & \\
\hline \multirow{3}{*}{ Wu's method [28] } & $S M_{1}=0.894$ & \\
& $S M_{2}=0.912$ & $a_{2} \succ a_{1} \succ a_{3}$ \\
& $S M_{3}=0.898$ & \\
\hline \multirow{3}{*}{ Proposed method } & $S M_{1}=0.963$ & \\
& $S M_{2}=0.974$ & $a_{2} \succ a_{1} \succ a_{3}$ \\
& $S M_{3}=0.966$ & \\
\hline
\end{tabular}

Table 4 Differences between the proposed method and Wang's method

\begin{tabular}{|c|c|c|}
\hline Comparative item & The proposed method & Wang's method [36] \\
\hline Initial information forms & HFLTSs & Linguistic terms \\
\hline Linguistic quantification methods & $\begin{array}{l}\text { Linguistic granulation optimization } \\
\text { method based on group similarity }\end{array}$ & Trapezoidal fuzzy number \\
\hline Generation of the attribute weight & $\begin{array}{l}\text { Reliability (group similarity and degree of } \\
\text { certainty) and prior subjective information }\end{array}$ & Prior subjective information \\
\hline Generation of the expert weight & $\begin{array}{l}\text { Reliability (degree of certainty) and } \\
\text { prior subjective information }\end{array}$ & Degree of grey relationship and the Euclid distance \\
\hline Generation of the stage weight & Not required & $\begin{array}{l}\text { A model by maximizing the distance among } \\
\text { alternatives and some subjective information }\end{array}$ \\
\hline Ranking reference criteria & Grade assessments and degree of certainty & Closeness coefficient \\
\hline
\end{tabular}

As is seen from Table 4, there are three main advantages of the proposed method by the comparison with Wang's method [36]: (i) the linguistic granulation optimization method is useful to obtain the higher degree of group similarity (see Table 3), enhancing the acceptability and credibility of the decision; (ii) it is not required for experts to provide additional evaluation information when determining the weight of stages; (iii) the reliability of both experts and attributes is considered in the fusion process, wherein the group conflict and uncertainty are both improved to enhance the decision-making validity.

Compared with Chen's method [18] and Wu's method [28], the method presented in this paper also has three advantages: (i) the method contributes to the higher degree of group similarity and thus increases the acceptability of the decision-making result; (ii) the reliability is measured by considering both group similarity and degree of certainty, which is useful to get an objective and high-quality decision; (iii) the proposed method can solve both the static and dynamic decision-making problems.

Thus, in the example, the result which is obtained by using the proposed method is more compelling.

\subsection{Discussion}

On the basis of the aforementioned calculation result and method comparison in the case, we discuss the advantages and disadvantages of the proposed approach in this section.

The concept of DHFLTSs is a useful tool to address dynamic decision-makings in which experts are allowed to have some hesitancy and express their information in a context-free grammar, so it can reduce the constraints on experts when expressing their opinions. The method to transform the DHFLTSs to proportional linguistic pairs can reduce the information loss or distortion but also help decision-makers clearly understand the performance distribution of alternatives. Moreover, this method can also reflex the development stability of alternatives with respect to each attribute, providing multiple reference criteria when making a selection. In order to comprehensively consider the real-word problems, this paper also provides a method to deal with the static decision-making problems.

As reliability is important on uncertain problems, it is measured by group similarity and certainty, aiming at reducing the adverse impact that is brought by group conflict and uncertainty, and thus reducing the decision-making risk. The optimization model (NLP 1) can deal with the situation when the linguistic terms are not uniformly and symmetrically distributed, and increase the degree of group similarity, which have been verified in Section 4.1. As a result, the proposed method renders a highly reliable deci- 
sion.

A drawback of the proposed approach is that the method cannot deal with the situation in which there exists the heterogeneous information. Fortunately, various studies have been developed to solve this kind of issue $[9,11,36]$.

\section{Conclusions}

The DHFLTSs method is studied from the perspective of information reliability. Based on the time dimension, the DHFLTSs are aggregated into the proportional linguistic terms. When aggregating the expert information, the expert reliability which is measured by group similarity and degree of certainty is considered into the fusion process. After calculating the amount of uncertainty which refers to the probability distribution, a method to determine the attribute stability as well as its reliability is proposed. Through aggregating the attribute information, the comprehensive expectation and degree of stability of alternatives are both considered to make a selection. Through the case study and method comparison, the validity and practicability of the proposed method are verified. Additionally, the proposed method has some features including clear concepts and easy computing steps that are applicable and scientific for uncertain problems, which provides a new direction for studying the decision-making reliability.

In addition to its application as described in the present paper, the proposed method can also be applied to other decision-making problems with uncertain information. Further study needs to provide approaches that are applicable to dynamic reasoning networks, dynamic decisionmaking with non-cooperative behaviors.

\section{Acknowledgements}

We quite appreciate the help from the co-authors as well as the members of my team both in University of Waterloo and Nanjing University of Aeronautics and Astronautics.

\section{References}

[1] WALLENIUS J, DYER J S, FISHBURN P C, et al. Multiple criteria decision making, multiattribute utility theory: recent accomplishments and what lies ahead. Management Science, 2008, 54(7): 1336-1349.

[2] SCHOLTEN L, SCHUWIRTH N, REICHERT P, et al. Tackling uncertainty in multi-criteria decision analysis - an application to water supply infrastructure planning. European Journal of Operational Research, 2015, 242(1): 243-260.

[3] CHITHAMBARANATHAN P, SUBRAMANIAN N. Service supply chain environmental performance evaluation using grey based hybrid MCDM approach. International Journal of Production Economics, 2015, 166: 163-176.

[4] GóMEZ-LIMóN J A, GUTIéRREZ-MARTíN C, RIESGO L. Modeling at farm level: positive multi-attribute utility programming. Omega, 2016, 65: 17-27.

[5] SAATY T L, PENIWATI K. Group decision making: drawing out and reconciling differences. Pittsburgh, USA: RWS Publi- cations, 2008.

[6] XU Y J, CHEN L, RODRIGUEZ R M, et al. Deriving the priority weights from incomplete hesitant fuzzy preference relations in group decision making. Knowledge-Based Systems, 2016, 99: $71-78$.

[7] MATTILA V, VIRTANEN K. Ranking and selection for multiple performance measures using incomplete preference information. European Journal of Operational Research, 2015, 242(2): $568-579$.

[8] LIN Y H, LEE P C, CHANG T P, et al. Multi-attribute group decision making model under the condition of uncertain information. Automation in Construction, 2008, 17(16): 792-797.

[9] MERIGóA J M, PALACIOS-MARQUéS D, ZENG S Z. Subjective and objective information in linguistic multi-criteria group decision making. European Journal of Operational Research, 2016, 248(2): 522-531.

[10] ZADEH L A. The concept of a linguistic variable and its application to approximate reasoning - I. Information Sciences, 1975, 8(3): 199-249.

[11] ZHU J J, ZHANG S T, CHEN Y. A hierarchical clustering approach based on three-dimensional gray relational analysis for clustering a large group of decision makers with double information. Group Decision \& Negotiation, 2016, 25(2): $325-$ 354.

[12] YAN H B, MA T J. A group decision-making approach to uncertain quality function deployment based on fuzzy preference relation and fuzzy majority. European Journal of Operational Research, 2015, 241(3): 815-829.

[13] RODRíGUEZ R M, MARTíNEZ L, HERRERA F. A fuzzy representation for the semantics of hesitant fuzzy linguistic term sets. WEN Z, LI T, ed. Foundations of Intelligent Systems. Berlin Heidelberg: Springer, 2014: 745-757.

[14] RODRíGUEZ R M, MARTíNEZ L, HERRERA F. A group decision making model dealing with comparative linguistic expressions based on hesitant fuzzy linguistic term sets. Information Sciences, 2013, 241: $28-42$.

[15] LIAO H C, XU Z S, ZENG X J. Hesitant fuzzy linguistic VIKOR method and its application in qualitative multiple criteria decision making. IEEE Trans. on Fuzzy Systems, 2015, 23(5): $1343-1355$.

[16] WANG J, WANG J Q, ZHANG H Y. Distance-based multicriteria group decision-making approaches with multi-hesitant fuzzy linguistic information. International Journal of Information Technology \& Decision Making, 2017, 16(4): $1069-$ 1099.

[17] DONG Y C, WU Y Z, ZHANG H J, et al. Multi-granular unbalanced linguistic distribution assessments with interval symbolic proportions. Knowledge-Based Systems, 2015, 82: 139151.

[18] CHEN Z S, CHIN K S, LI Y L, et al. Proportional hesitant fuzzy linguistic term set for multiple criteria group decision making. Information Sciences, 2016, 357: 61 -87.

[19] VAN HORENBEEK A, PINTELON L. Development of a maintenance performance measurement framework - using the analytic network process (ANP) for maintenance performance indicator selection. Omega, 2014, 42(1): 33-46.

[20] SALAMANCA H E, QUIROZ L L. A simple method of estimating the maintenance cost of airframes. Aircraft Engineering \& Aerospace Technology, 2005, 77(2): 148-151.

[21] CHENGALUR-SMITH I N, BALLOU D P, PAZER H L. The impact of data quality information on decision making: an exploratory analysis. IEEE Trans. on Knowledge \& Data Engineering, 1999, 11(6): 853-864.

[22] FU C, YANG J B, YANG S L. A group evidential reasoning approach based on expert reliability. European Journal of Operational Research, 2015, 246(3): 886-893. 
[23] LIN G P, LIANG J Y, QIAN Y H. An information fusion approach by combining multigranulation rough sets and evidence theory. Information Sciences, 2015, 314: 184-199.

[24] SARABI-JAMAB A, ARAABI B N, AUGUSTIN T. Information-based dissimilarity assessment in DempsterShafer theory. Knowledge-Based Systems, 2013, 54: 114 127.

[25] PéREZ I J, CABRERIZO F J, ALONSO S, et al. A new consensus model for group decision making problems with nonhomogeneous experts. IEEE Trans. on Systems Man \& Cybernetics Systems, 2014, 44(4): 494-498.

[26] ZHANG G Q, DONG Y C, XU Y F. Consistency and consensus measures for linguistic preference relations based on distribution assessments. Information Fusion, 2014, 17: 46-55.

[27] ZHU B, XU Z S. Consistency measures for hesitant fuzzy linguistic preference relations. IEEE Trans. on Fuzzy Systems, 2014, 24(1): $72-85$.

[28] WU Z B, XU J P. Possibility distribution-based approach for MAGDM with hesitant fuzzy linguistic information. IEEE Trans. on Cybernetics, 2016, 46(3): 694-705.

[29] KLIR G J, YUAN B. Fuzzy sets and fuzzy logic: theory and applications. Upper Saddle River: Prentice-Hall, 1995.

[30] JOUSSELME A L, LIU C S, GRENIER D, et al. Measuring ambiguity in the evidence theory. IEEE Trans. on Systems Man \& Cybernetics, Part A: Systems \& Humans, 2006, 36(5): $890-903$.

[31] FRIKHA A. On the use of a multi-criteria approach for reliability estimation in belief function theory. Information Fusion, 2014, 18: 20-32.

[32] DONG Y C, ZHANG H J, HERRERA-VIEDMA E. Consensus reaching model in the complex and dynamic MAGDM problem. Knowledge-Based Systems, 2016, 106: 206-219.

[33] PENG D H, WANG H. Dynamic hesitant fuzzy aggregation operators in multi-period decision making. Kybernetes, 2014, 43(5): $715-736$.

[34] DONG Y C, LI C C, HERRERA F. Connecting the linguistic hierarchy and the numerical scale for the 2-tuple linguistic model and its use to deal with hesitant unbalanced linguistic information. Information Sciences, 2016, 367/368: 259-278.

[35] ZHU J J, HIPEL K W. Multiple stages grey target decision making method with incomplete weight based on multigranularity linguistic label. Information Sciences, 2012, 212: $15-32$.

[36] WANG H H, FANG Z G, ZHU J J. An extension of grey target method with multistage fuzzy linguistic evaluation under incomplete weight. Kybernetes, 2012, 41(5/6): 736-749.

[37] DONG Y C, ZHANG H J, HERRERA-VIEDMA E. Integrating experts' weights generated dynamically into the consensus reaching process and its applications in managing noncooperative behaviors. Decision Support Systems, 2016, 84: $1-15$.

[38] DONG Q X, COOPER O. A peer-to-peer dynamic adaptive consensus reaching model for the group AHP decision making. European Journal of Operational Research, 2016, 250(2): $521-530$.

[39] HARTLEY R V L. Transmission of information. Bell Labs Technical Journal, 1928, 7: 535-563.

[40] MAEDA Y, NGUYEN H T, ICHIHASHI H. Maximum entropy algorithms for uncertainty measures. International Journal of Uncertainty, Fuzziness and Knowledge-Based Systems, 1993, 1(1): 69-93.

[41] DONG Y C, HERRERA-VIEDMA E. Consistency-driven automatic methodology to set interval numerical scales of 2-tuple linguistic term sets and its use in the linguistic GDM with preference relation. IEEE Trans. on Cybernetics, 2015, 45(4): $780-792$.
[42] RODRíGUEZ R M, MARTíNEZ L. An analysis of symbolic linguistic computing models in decision making. International Journal of General Systems, 2013, 42(1): 121-136.

[43] WEI G W. Grey relational analysis method for 2-tuple linguistic multiple attribute group decision making with incomplete weight information. Expert Systems with Applications, 2011, 38(5): $4824-4828$.

[44] HERRERA-VIEDMA E, CABRERIZO F J, KACPRZYK J, et al. A review of soft consensus models in a fuzzy environment. Information Fusion, 2014, 17: 4-13.

[45] LARSON R, EDWARDS B. Calculus. 9th ed. Boston, USA: Cengage Learning, 2009.

[46] YANG J B, XU D L. Evidential reasoning rule for evidence combination. Artificial Intelligence, 2013, 205: 1-29.

[47] GARDI A, SABATINI R, RAMASAMY S. Multi-objective optimisation of aircraft flight trajectories in the ATM and avionics context. Progress in Aerospace Sciences, 2016, 83: $1-36$.

\section{Biographies}

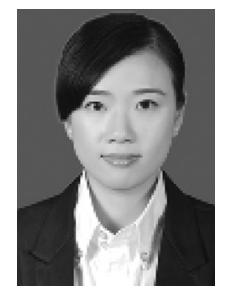

MA Zhenzhen was born in 1988. She is a Ph.D. candidate in management science and engineering from Nanjing University of Aeronautics and Astronautics, Nanjing, China. She studied as a visiting scholar with the Department of Systems Design Engineering, University of Waterloo, Waterloo, ON, Canada from 2016 to 2017 . Her current research interests include group decision-making, soft computing, multicriteria decision analysis and applications.

E-mail: zhenzhen5886@163.com

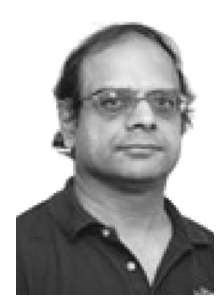

PONNAMBALAM Kumaraswamy was born in 1958. He received his Ph.D. degree from University of Toronto, Toronto, ON, Canada, in 1987. He is a professor with the Department of Systems Design Engineering, University of Waterloo, Waterloo, ON, Canada. His research interests include the development of design optimization under uncertainty, decision analysis and its applications.

E-mail: ponnu@uwaterloo.ca

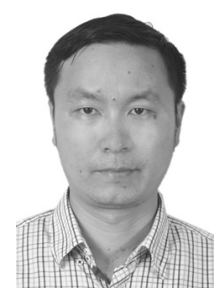

ZHU Jianjun was born in 1976. He received his $\mathrm{Ph} . \mathrm{D}$ degree in systems engineering, Northeastern University, Shenyang, China, in 2005 . He is a professor with the College of Economics and Management, Nanjing University of Aeronautics and Astronautics, Nanjing, China. His current research interests include the multiple-criteria decision analysis and its applications, decision support systems, and supply chain coordination and modeling.

E-mail: zhujianjun@nuaa.edu.cn

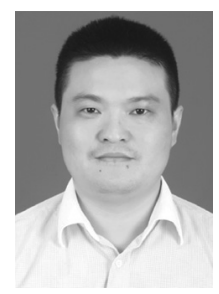

ZHANG Shitao was born in 1980 . He received his $\mathrm{Ph} . \mathrm{D}$. degree in management science and engineering from Nanjing University of Aeronautics and Astronautics, China, in 2017. He is a lecturer at the School of Mathematics and Physics, Anhui University of Technology, China. His current research interests include group decision making, consensus, computing with words, and decision support systems.

E-mail: zhangshitao1980@126.com 